$\Phi=-\Phi^{\infty}$

\title{
Per capita income and public health expenditure: what makes good child health outcomes in Tanzania? a comparison of Frequentist and Bayesian approach (1995-2013)
}

\author{
Mwoya Byaro*, Patrick Musonda \\ Department of Public Health, University of Zambia,P.O. Box 50110, Lusaka \\ *Corresponding author E-mail:byaro2014@yahoo.com
}

\begin{abstract}
Using data for World Bank Development Indicators (2015) database from 1995 to 2013, this paper explores the impact of public health expenditure on national health outcomes in Tanzania while GDP per capita and improved sanitation facilities as explanatory variables were controlled for. Two national health outcomes indicators namely, infant and under-five mortality were used as dependent variables. With separate modeling approach, Frequentist and Bayesian based on time series and Markov Chain Monte Carlo (MCMC) respectively, empirical evidence shows that income, represented by real GDP per capita lower infant and under-five mortality in Tanzania. Under both methodological approach regardless of the sample size, we failed to support evidence that, public health expenditure and improved sanitation facilities had an impact on child health outcomes. Our results imply that, public health spending in Tanzania is poorly targeted to bring good child health outcomes. The paper draws attention to policy makers in Tanzania to focus either within public health spending composition or beyond to other close determinants of infant and under-five mortality.
\end{abstract}

Keywords: Bayesian; Frequentist; Health Outcomes; Public Spending.

\section{Introduction}

The performance of a country health system lies with government (World Health Report, 2000). Health system performance in many countries differs, as some countries perform well while others perform poorly (World Health Report, 2000). This implies that the primary goal of government financial resource (that is public health expenditure categories), and health care system is to improve the health of the population they serve (Kim \& Lane, 2013; World Bank Report, 2000). The fundamental responsibility of any government is to improve overall management processes starting from financial resources (expenditure categories, budget elements, health system inputs: those are human resources) leading to better health outcomes. Better health outcomes for people are always a national priority that any government has to handle properly. Every year, government spends money on health to impact the poor, because the poor are likely to obtain health services at public health facilities (Gupta et al., 2003).

Countries with similar level of development, public health spending differs greatly in health outcomes measures (World Health Report, 2000). For instance, with the same level of resources; one country can generates better health outcomes than another country, or generates the same outcomes with fewer resources (Elola et al., 1995). Our primary question is what makes good health outcomes (infant and under-five mortality) between per capita income and public health expenditures in Tanzania? This question may help policy makers to understand among others the factors that make a difference to health outcomes. Therefore, our paper explores the relationship between health outcomes, per capita income and public health expenditures in Tanzania.
Many studies examined the link between public health expenditure and health outcomes (infant and under-five mortality). These studies do not agree with each other, while others found a clear relationship (Emamgholipour \& Asemane, 2016, Boachie \& Ramu, 2016, Basu et al., 2015, Akinci et al., 2014, Singh, 2014, Kim \& Lane, 2013, Dieleman, 2013, Cevik \& Tasar, 2013, Novignon et al., 2012, Akinkugbe \& Mohanoe, 2009, Gani, 2008, Anywanu \& Erhijakpor, 2007, Bokhari et al. 2007, Nixon \& Ulmann 2006, Issa \& Quattara, 2005, Gupta et al., 2002) others found no relationship between public health expenditure and health outcomes (Ssozi \& Amlani, 2015, Deluna \& Peralta, 2014, Yaqub et al., 2012, McGuire, 2006, McGuire, 2002, Filmer \& Pritchett, 1999, Burnside \& Dollar, 1998, Musgrove, 1996, Kim \& Moody, 1992).

The majority of studies examined the effect of public health expenditure on health outcomes were based on estimates of combining either developing or developed countries using panel data (for example, Akinci et al., 2014, Deluna \& Peralta, 2014, Kim \& Lane, 2013, Cevik \&Tasar, 2013, Dieleman, 2013, Novignon et al., 2012, Bokhari et al., 2007, Gani, 2008, Nixon \& Ulmann, 2006, Filmer \& Pritchett, 1999). Studies intended specifically on single countries are very limited (for example, Boachie \& Ramu, 2016, Yaqub et al., 2010, Akinkugbe \& Mohanoe, 2009). Studies combining countries with different levels of development and health outcome indicators do not provide a unique picture of each country's characteristics. Single country studies are useful to estimate the relationship between public health expenditure and health outcomes because it might inform domestic policies and build national strategic plans.

Methodologies used in different studies differ in sample size, time periods and variables selection. Various authors have pointed out problems with sample size, especially those that applied frequentist approach to study the effect of public health expenditure 
on health outcomes. Among them (for example, Dieleman, 2013) argued about ill-powered sample size used and simultaneity problem encountered between GDP per capita and public health expenditure( Akinci et al., 2014, and Barenberg et al., 2015) thus requiring instrumental variables or using two stages least-squares regression model to overcome endogeneity. Dieleman, (2013) claimed that studies linking between public health expenditure and health outcomes might be due to small sample size such as that by Anand \& Ravalion,(1993), Filmer \& Pritchett, (1999) used less than 100 observations.

This paper contributes to this literature by comparing both Bayesian Approach and Frequentist Approach (that is, the time-series analysis) in studying the impact of public health expenditure on health outcomes in Tanzania. The reason for incorporating the Bayesian analysis is to get reliable estimation results when a researcher doubts about endogeneity and also to address the problem of sample size and simultaneity bias experienced in previous research and to find whether different methodologies and sample size results to different relationship. Frequentist approach intended to compare the low ill-power problems due to small data sets as argued by Dieleman, (2013) and other researchers using small data sets of less than 30 observations (Anand \& Ravallion, 1993, Hojman, 1996, Boachie et al., 2016) for example used small sample sizes of 22 observations, 10-20 observations, and 22 observations respectively.

The advantage of the Bayesian approach over the frequentist is to estimate parameters based upon observed data by simulating a small sample using Markov Chain Monte-Carlo (MCMC) getting up to 10,000 samples to give posterior distribution, which can provide stronger statistical power. Thus, the Bayesian approach can be used regardless of the sample size meaning that, the sample size does not affect inference method (Kruschke et al., 2012).

Using data for World Bank Development Indicators (2015) in Tanzania for the years 1995-2013, first we present frequentist (that is, the time series) approach unit root tests for government health expenditure, real GDP per capita, infant mortality, under-five mortality and improved sanitation facility's variables based on the Augmented Dickey-Fuller (ADF) test of non-stationarity. We also present the Bayesian methods to determine whether or not the results from simulation by Markov Chain Monte Carlo based on large samples are an efficient predictor of the impact of public health expenditure on health outcomes (infant and under-five mortality). Then, we compare the two sets of findings and report our conclusion based on the implication for modeling impact of public health expenditure on health outcomes (infant and under-five mortality) in Tanzania.

Based on the results of both approaches, conclusively, we fail to support the evidence that, public health expenditure had a negative impact on health outcomes. Instead, we found income represented by real GDP per capita to have a positive impact in lowering infant and under-five mortality. The results of our findings in both Frequentist and Bayesian approach revealed that, improved sanitation facilities were not associated with reduced infant and under- five mortality. We obtained the results after performing several sensitivity tests as required by each approach, and finally we argue that the sample size of 19 observations for frequentist still provided enough statistical significant results of variables of interest. However, results obtained by Bayesian inference produce more accurately estimated of the parameters described. The rest of the paper is organized as follows: section 2 describes the model and data sources. Section 3 presents theoretical literature review. Section 4 summarizes the results and discussion while section 5 concludes the paper.

\section{Model and data sources}

Starting with frequentist approach, we followed Boachie and Ramu, (2016) model of health status as follows:

$\mathrm{Y}_{\mathrm{t}}=\beta \mathrm{X}_{\mathrm{t}}+\varepsilon_{\mathrm{t}}, \mathrm{t}=1 \ldots \ldots \mathrm{T}$

$Y_{t}=$ Dependent variables (infant and under- five mortality rate) at time $\mathrm{t}$

$X_{t}=$ Vector of independent variables influencing health status at time $\mathrm{t}$

$\varepsilon_{\mathrm{t}}=$ Normal distributed error term with zero means and constant variance

Then the simplified model became

$Y_{t}=\gamma+B_{1} P E_{t}+B_{2} G P_{t}+B_{3} I M S_{t}+\varepsilon_{t}$

Where PHE represents public health expenditure as \% share of GDP, GDP represents Gross Domestic Product per Capita at constant 2005 US dollars; IMS represents improved sanitation facilities (\% of population with access).

Since the dependent variables $\left(\mathrm{Y}_{\mathrm{t}}\right)$ involves two health outcomes, two model were estimated for both infant and under-five mortality rates. To capture the elasticity and correcting skewness in the data, we introduced natural logarithm form in equation (2) and the model became:

$\mathrm{LNY}_{\mathrm{t}}=\mathrm{\gamma}+\mathrm{LNB}_{1} \mathrm{PHE}_{\mathrm{t}}+\mathrm{LNB}_{2} \mathrm{GDP}_{\mathrm{t}}+\mathrm{LNB}_{3} \mathrm{IWS}_{\mathrm{t}}+\varepsilon_{\mathrm{t}}$

We followed linear and $\log$-log specifications functional forms used previously in other literature for ease interpretation of our results (Boachie \& Ramu, 2016, Cevik \& Tasar, 2013, Filmer \& Pritchett, 1999, Pritchett \& Summers, 1996, Gupta et al., 2002). Running regression in log-log form provide similar result to those of the linear form (Gupta et al., 2002). Elasticity is described as a percentage change in one variable for a $1 \%$ change in other variables (Cevik \& Tasar, 2013, Filmer \& Pritchett, 1999) and is easily comparing empirical results as scale neutral. Details on all variables sources and definition are described in Table 1.

Table 1: Variable Definition and Data Sources

\begin{tabular}{|c|c|c|}
\hline Variable & Definition & Source \\
\hline Infant mortality & $\begin{array}{l}\text { The number of infants dying before reaching } 1 \text { year of age per } 1000 \text { live births in a given } \\
\text { year. }\end{array}$ & $\begin{array}{l}\text { World Bank Development Indi- } \\
\text { cators } 2015\end{array}$ \\
\hline Under -five mortality & $\begin{array}{l}\text { The probability that a newborn will die before reaching age } 5 \text { expressed as a rate per } 1000 \\
\text { children under age } 5\end{array}$ & $\begin{array}{l}\text { World Bank Development Indi- } \\
\text { cators } 2015\end{array}$ \\
\hline GDP per capita & Gross Domestic Product per capita, real (constant 2005 international \$) & $\begin{array}{l}\text { World Bank Development Indi- } \\
\text { cators } 2015\end{array}$ \\
\hline PHE (\% of GDP) & Ratio of public health expenditure on health care to GDP & $\begin{array}{l}\text { World Bank Development Indi- } \\
\text { cators } 2015\end{array}$ \\
\hline $\begin{array}{l}\text { Improved sanitation } \\
\text { facilities (\% of popula- } \\
\text { tion with an access) }\end{array}$ & $\begin{array}{l}\text { Proportion of population in urban and rural that are regularly using a private sanitary } \\
\text { facility for human excreta disposal in the dwelling }\end{array}$ & $\begin{array}{l}\text { World Bank Development Indi- } \\
\text { cators } 2015\end{array}$ \\
\hline
\end{tabular}


standard errors of coefficients on explanatory variables using correlation analysis.

The paper used control variables (GDP per capita and improved sanitation facilities) due to the fact that, increase in GDP per capita improves population health outcomes (Gupta et al., 2002, Filmer \& Pritchett, 1999). Furthermore, increased access to sanitation improves health status (child and infant mortality) statistically significant (Kim \& Moody, 1992, Hojman, 1996).

Our study used annual time-series data from 1995 to 2013. Data limitations for Tanzania prevent adding other control variables such as socioeconomic indicators that may affect health status (that is, female literacy). All data were drawn from the World Bank Development Indicators database (2015).

\subsection{Unit root tests for frequentist approach}

A stationary test was applied by Augmented Dickey-Fuller test to both dependent and independent variables. The unit root test showed that public health expenditure, improved sanitation facilities, real GDP per capita, infant and under-five mortality variables are non-stationary at levels. However, after taking the first difference and observing Partial Autocorrelation Correlogram (PAC), all variables became stationary. In time series analysis, using linear regression model without testing the unit root leads to spurious regression (Gujarati, 2004).

\subsection{Bayesian approach (Markov chain Monte-Carlo)}

\subsubsection{Model specification}

The same variables pointed out in frequentist approach were used for Bayesian model. In Bayesian model building, we incorporated three components which are likelihood, prior and given data set to provide final results which are posterior distributions. According to (Ntzoufras, 2009) the likelihood part of the multiple linear regression models can be viewed as

$y_{i} \sim \mathrm{N}\left(\mu_{i},{ }\right.$, where $\mu_{i}=X^{\prime}{ }_{i} \beta, \quad \mathrm{i}=1 \ldots, \mathrm{n}$ and $\tau=\frac{1}{\sigma 2}$

Where $y_{i}=$ dependent variables for mortality rate (infant and under-five mortality rate)

$X^{\prime}{ }_{i}=$ vector of explanatory variables (Public health expenditure, GDP per capital \& improved sanitation facilities)

$\beta=$ Coefficient of unknown parameter

$\mu_{i}=$ represent mean,

$\tau=$ represent precision or tau

The prior distribution assumed is

$P(\beta, \tau)=\prod_{j=0}^{k} P\left(\beta_{j}\right) P(\tau)$

Where $\beta_{j} \sim N\left(\mu_{\beta_{j}}, c_{j}^{2}\right)$ and $\tau \sim \operatorname{gamma}(a, b)$

The resulting posterior density is given by:

$P\left(\beta_{0}, \beta_{i}, \tau / y\right) \propto P\left(y / \beta_{0}, \beta_{i}, \tau\right) P(\beta, \tau)$
Where $\beta_{0}, \beta_{i}$, represents the set of unknown parameter $\theta$, y represents the data; $P(\beta)$ is the prior distribution of the parameter which is derived from theoretical or other prior knowledge. $\mathrm{P}\left(\mathrm{y} / \beta_{0}, \beta_{\mathrm{i}}, \tau\right)$ is the likelihood function which describes data $\mathrm{y}$ given unknown parameter $\beta_{0}, \beta_{i}$.

$\mathrm{P}\left(\beta_{0}, \beta_{\mathrm{i}}, \tau / \mathrm{y}\right)$ is the posterior distribution for unknown parameter $\beta_{0}, \beta_{i}$,given the data $y$.

Two different Bayesian models was analysed since dependent variables includes two health outcomes (infant and under age-five mortality). From the Bayesian model, the MCMC utilizes time series because; it's set up contains all information to time $t$ and for time t-1 (Quintana \&Nason, 2012).

\subsection{Data analysis}

For both data sets, we used Bayesian approach based on Markov Chain Monte Carlo (MCMC) methods in WinBUGS1.4 and Frequentist approach in Stata Version 12 statistical packages. For the Bayesian approach, the data was drawn with a normal distribution of mean, $m u$ and precision $t a u$. $M u$ is given a normal prior with mean 0 and precision 0.001 , and tau is given a gamma $(0.0,0.01)$. The estimation method was based on Markov Chain Monte Carlo (MCMC) simulation to get posterior distribution. We run 10,000 iterations sample with a burn in of 1000 and 1 thinning parameter. The iteration was important to observe and monitor stationary distribution (convergences). Similarly, thinning is done to reduce autocorrelations which is common in time series data.

To see whether the model was appropriate, diagnosis test performed based on MCMC post estimation through history plots, autocorrelation plots and kernel density. Kernel density is done to observe normal distribution of the parameters. All the models were free from autocorrelation, showed normal distribution and convergence to equilibrium, thus ready for interpretation.

\section{Theoretical literature review}

Our paper is based on a conceptual framework adopted from World Bank Report, (2000). The total public health spending described in this study is the sum of all total financial resources flows in the government health sector that leads to production of health interventions to get better health outcomes. Health care services depend on resource inputs to deliver health service outputs.This means that financial resources play a greater role to determinants of health status outputs. Good health is a combination of health inputs to deliver health outcomes and that entirely depends on financial resources. Figure 1, shows health system input from financial resources to health intervention. The total financial resources flow into capital expenditure for investments in buildings and equipment. Recurrent expenditure pays for health care staff and human capital, maintenance of physical capital while other recurrent expenditure is used for consumable inputs (that is, pharmaceuticals). 


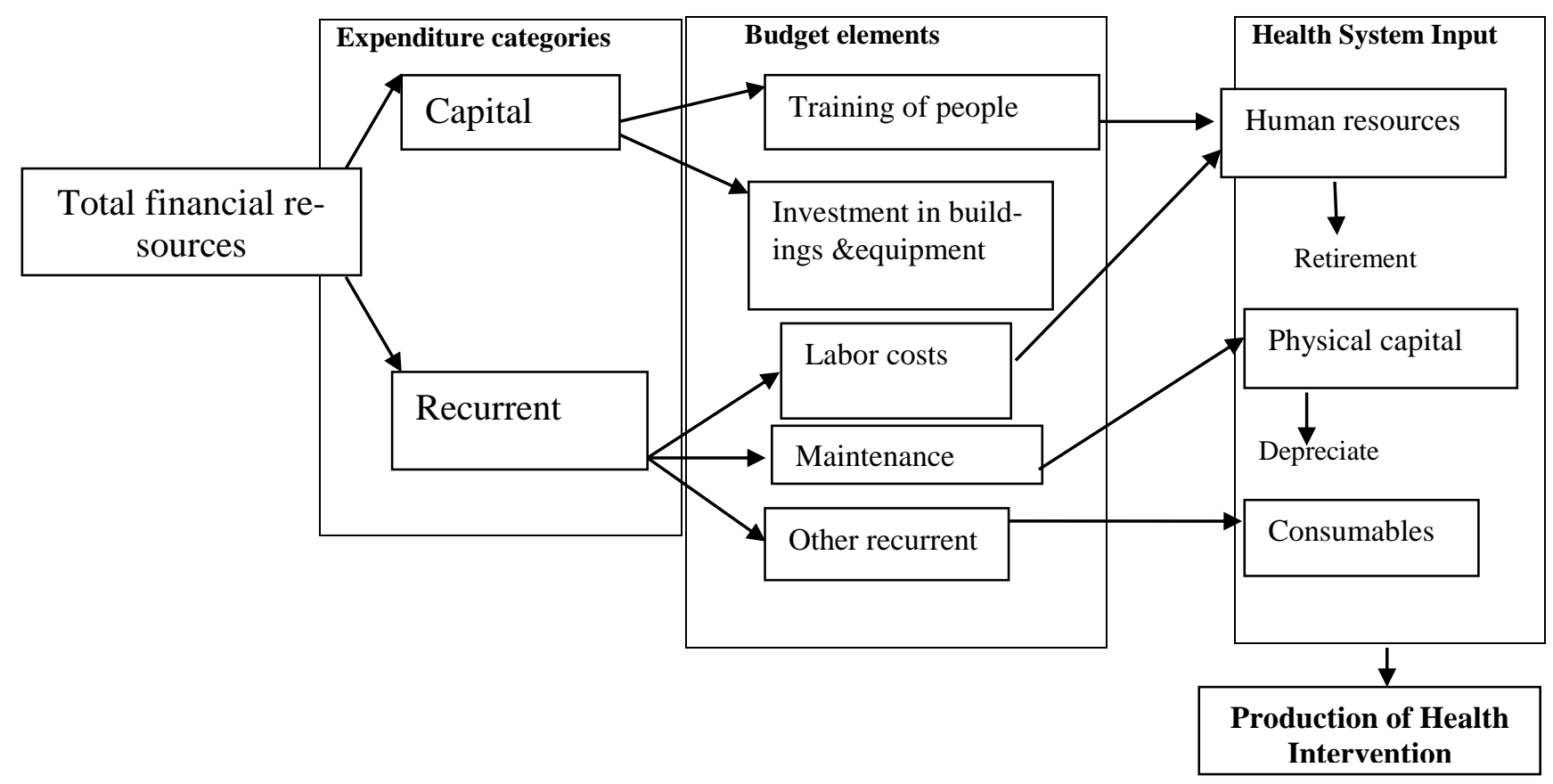

Fig. 1: Health System Input from Financial Resources to Health Intervention Source: (Adapted from World Health Report, 2000).

\section{Empirical results and discussion}

\subsection{Results}

Figure 2 and Figure 3 present trends and averages of public health spending and GDP per capita in Tanzania over the years (19952013). Figure 2 shows that, the average share of public health expenditure in Tanzania had never gone beyond 4\% of GDP given at 2005 constant dollar. Over the years (1995-2013), an average public health spending (in percentage of GDP) was $2.08 \%$. This expenditure remained below $2 \%$ from 1995 to 2005 . Substantial increases arise in 2006 to 2013 implying improvements in financial resources and health care system. However, at the low incomes countries likely Sub-Saharan Africa and poor countries of Asia, total public health spending is about 3- 4\% of GDP (Musgrove, 1996). In 2010, the average public health expenditure as percentage of GDP was 3\% in Sub-Saharan Africa, compared to world average of $6 \%$, North America $8 \%$ (Novignon et al., 2012).

Figure 3 shows the trend of average GDP per capita at constant US \$. Average GDP per capita increases from 345.4 US \$ in $1995-2000$ to 517.03 US \$ in 2006-2013. This indicates citizen's improvement in standard of living and their economic welfare including ability to afford health services (health care, better nutrition, better housing and clean water). Generally, higher per capita GDP generates more incomes for people and other basic needs (McGuire, 2006).

Figure 4 shows that, the average of infant mortality declined from 89 deaths per 1000 live births in 1995 to approximately 45 deaths per 1000 live births in 2013. The average under-five mortality has been reduced from approximately 146 deaths per 1000 live births in 1995 to 67 deaths per 1000 live births in 2013. In general, there is improvement in health outcomes in Tanzania from 1995-2013.
Table 2 shows the correlation matrix of variables used in this study. Correlation coefficient was used to measure the strength of the linear relationship between two variables before deciding to estimate regression model in the frequentist approach to avoid multicollinearity. It was estimated after transforming the variables under $\log -\log$ and differencing to stationary. As shown in (Table 2 ), infant and under-five mortality were negative and significantly associated with GDP per capita and improved sanitation facilities $(\mathrm{P}<0.05)$. In turn, public health expenditure was not significantly correlated with both infant and under-five mortality $(\mathrm{P}>0.05)$.

Table (2) shows that, the multiple correlations among other explanatory variables (public health expenditure, GDP per capita and improved sanitation facilities) which reduce statistical power were not a serious problem as revealed by the low correlation coefficients from the correlation coefficient matrix. After testing multicollinearity and unit roots test using Augmented Dickey Fuller Test (ADF), then Newey-West regression analysis was estimated to overcome autocorrelations and heteroskedasticity that might present in the error terms of the given models (See equation 3).

Based on frequentist approach (Table 3), the elasticity of income (GDP per capita) is -0.67 for infant and -0.69 for under-five mortality. This means that, a $10 \%$ increase in income (GDP per capita) reduce infant mortality by $6.7 \%$. Moreover, $10 \%$ increases in per capita income reduce under-five mortality approximately by $6.9 \%$. The estimated elasticity for mortality with respect to income was closely as reported by Filmer \& Pritchett, (1999). They reported the elasticity of child mortality with respect to income of around 0.6 using cross sectional or time series national level data. In general our results show that, income represented by Gross Domestic Product (GDP) per capita is an important determinant of child survival in Tanzania. Public health expenditure and improved sanitation facilities were not significant in reducing infant and under-five mortality in Tanzania. 


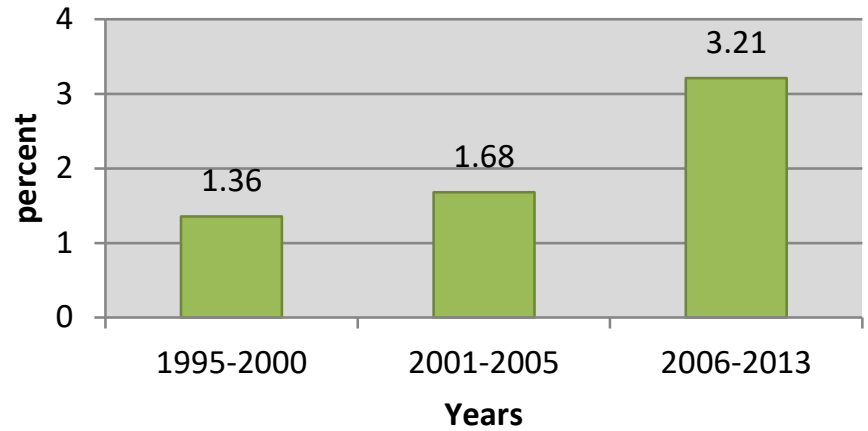

Average health expenditure, public (\% of GDP)

Fig. 2:Trends of Average Public Health Spending (\% of GDP) in Tanzania.

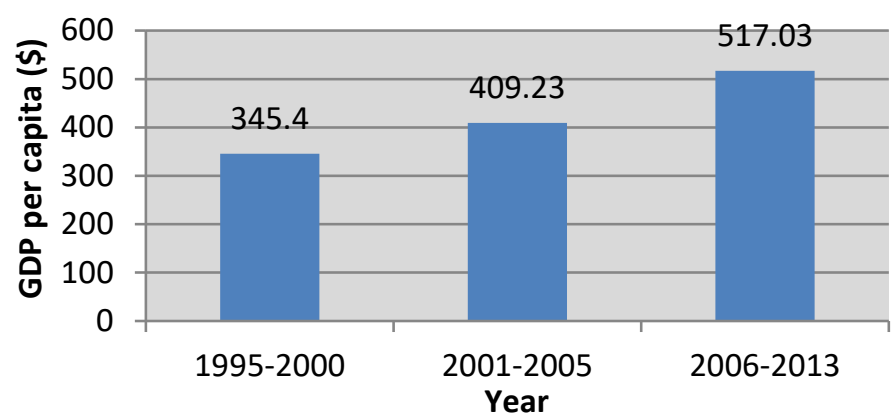

Average GDP per capita at constant US \$

Fig. 3:Average GDP Per Capita (at Constant 2005 US \$) in Tanzania.

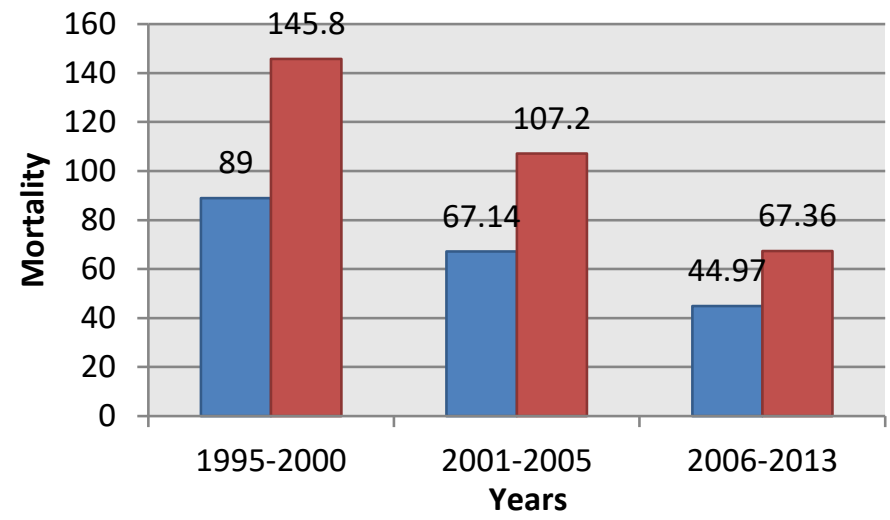

Infant mortality per 1000 live births

$\square$ under five mortality per 1000 live births

Fig. 4: Selected Health Outcome Indicators in Tanzania, 1995-2013(Country Average).

Table 2: Correlation Coefficient Matrix

\begin{tabular}{|c|c|c|c|c|c|}
\hline & Improved sanitation facilities & Infant mortality & Under five mortality & GDP per capital & Public health expenditure \\
\hline Public health expenditure & $\begin{array}{l}-0.20 \\
(0.42)\end{array}$ & $\begin{array}{r}0.10 \\
(0.69)\end{array}$ & $\begin{array}{l}0.07 \\
(0.78)\end{array}$ & $\begin{array}{l}-0.03 \\
(0.89)\end{array}$ & 1.00 \\
\hline GDP per capita & $\begin{array}{c}0.38 \\
(0.11)\end{array}$ & $\begin{array}{l}-0.65 \\
(0.00)^{*}\end{array}$ & $\begin{array}{l}-0.57 \\
(0.01)^{*}\end{array}$ & 1.00 & $\begin{array}{l}-0.03 \\
(0.89)\end{array}$ \\
\hline
\end{tabular}

Note: Values in ( ) are p - value at $95 \%$ level of significance, and * statistically significant.

Table 3: Newey-West Regression Model for Frequentist Approach

\begin{tabular}{|c|c|c|c|c|}
\hline & (Infant Mortality) & & (Under- Five & \\
\hline Independent variable & Coefficient & P-values & Coefficient & P-values \\
\hline Public HE & -0.055 & 0.377 & -0.008 & 0.070 \\
\hline GDP & -0.673 & $0.015^{*}$ & -0.688 & $0.018^{*}$ \\
\hline IMP & -0.012 & 0.854 & -0.071 & 0.290 \\
\hline
\end{tabular}

Note: $\mathrm{P}$-values indicates $5 \%$ significance levels, $\mathrm{P}<0.005$; Maximum lag used=2 and * statistically significant.

Given evidence in (Table 3), our results agree with Musgrove, (1996) statement that "multivariate estimates of the determinants of child mortality give much the same answer:Income is always significant, but the health share in GDP, the public share in health spending and the share of public expenditure on health in GDP never are" (p.44). In the same vein, Filmer et al., (2000) and McGuire, (2006) agreed to similar conclusion. In turn, Demery and Walton, (1998) noted that "the conclusion that public spend- 
ing is a poor predictor of good health is a common one" (p.26).The given statements by Musgrove, (1996), Demery \& Walton, (1998) are justified on the relationship between public health expenditure and health outcomes by comparing the results of Bayesian and Frequentist Approach in (Table 4 \& 5).

Results in Tables (3, 4 \& 5) contradict with Dieleman, (2013) arguments of the small sample size of previous studies. For example, Anand \& Ravallion, (1993), Hojman, (1996), Boachie et al., (2016) used small sample sizes of 22 observations, 10-20 observations, and 22 observations respectively still found public health spending to had statistically significant effect on health status. Our results show that the effect size in this case seems to be large given that even sample size within 19 observations one could rule out chance findings for frequentist analysis.

In Tables ( $4 \& 5$ ), Bayesian estimators outperform the maximum likelihood estimator with respect to coverage of $95 \%$ credible intervals over $95 \%$ confidence intervals respectively. This means that, the coefficients of variable of interest within Frequentist approach (95\% Confidence Intervals) lie within the Bayesian (95\% Credible Intervals). In contrast, the results of Bayesian and Fre- quentist Approach in interpretation are almost the same. For instance, in terms of parameter coefficient estimates and signs of GDP per capita for Bayesian is similar to frequentist though Bayesian interval estimation produces results with precision greater than or almost equal to frequentist method (See Table $4 \& 5$ ).

The summary results of the Bayesian models (Table $4 \& 5$ ) are interpreted within the credible intervals and the association between explanatory variables and dependent variables are observed on the signs of the posterior summaries (mean and $95 \%$ credible intervals).

If the sign of posterior summaries are all positive or negative, then the corresponding association is achieved. The result from (Table 4 \&5) implies that, the mean for income represented by (GDP per capita) corresponds to both infant and under-five mortality decline. In contrast, there were no corresponding associations that shows improved sanitation facilities and public health expenditure had an impact on infant and under-five mortality (See Table 4 \& 5).

Table 4: Comparison Summary Results for Bayesian and Frequentist for Under-Five Mortality

\begin{tabular}{lllcllc}
\hline Bayesian Approach & \multicolumn{5}{c}{ Frequentist Approach } \\
\hline Variable & Mean & \multicolumn{2}{c}{$95 \%$ (Credible intervals) } & Coefficient & $95 \%$ (Confidence Intervals) \\
Public HE & 0.002 & -0.098 & 0.106 & -0.088 & -0.185 & 0.008 \\
GDP & -1.409 & -2.491 & -0.295 & -0.688 & -1.241 & -0.136 \\
IMP & -0.546 & -1.558 & 0.434 & -0.071 & -0.211 & -0.067 \\
\hline
\end{tabular}

Note: HE represents health expenditure; GDP represents real GDP per capita (income); IMP represents improved sanitation facilities; Mean for Bayesian represents coefficient in frequentist.

Table 5: Comparison Summary Results for Bayesian and Frequentist for Infant Mortality

\begin{tabular}{lllllc}
\hline Bayesian Approach & \multicolumn{5}{c}{ Frequentist Approach } \\
\hline Variable & Mean & $95 \%$ (Credible intervals) & Coefficient & $95 \%$ (Confidence Intervals) \\
Public HE & -0.020 & -0.113 & 0.076 & -0.055 & -0.018 \\
GDP & -1.062 & -2.664 & -0.031 & -0.673 & -1.197 \\
IMP & -0.60 & -1.54 & 0.307 & -0.012 & -0.149 \\
\hline
\end{tabular}

Note: Mean $=$ posterior mean

\subsection{Discussion}

The main purpose of this study was to examine whether GDP per capita or public health expenditure improves child health outcomes (infant and under-five mortality) in Tanzania for a period between 1995 and 2013 using world Bank Development Indicators (2015).

Our study shows no evidence that public health expenditure and improved sanitation facilities had an impact on infant and underfive mortality in Tanzania. The finding contradicts with previous studies due to a number of circumstances. First, is the misallocation of public health resources in the health sector that might not be utilized in a prompt manner in the sense that many funds are directed to build capital infrastructure like dispensary or maternity wards, without providing necessary health facility tools and health personnel (that is, medical doctors, clinical officers and nurses/midwives). Even if health facilities and personnel are available, infrastructure such as roads and transport are poor. For instance, Wagstaff \& Claeson, (2004) argued that, increasing government spending on health care may not result to better health outcomes unless addition funds are spent to high productivity inputs or services with complementary network (for example, more hospitals and clinics accompanied with road network services). The reason that public health expenditure failed to reduce infant and underfive mortality has been attributable to poor policy and weak institutions (Wagstaff \& Claeson, 2004, Filmer et al., 2000, Burnside \& Dollar, 1998). Another reason is about consumers' willingness to make a choice about the type of health services. For instance, if public health facilities capital infrastructure is located in remote areas and transport cost is too high, while the health services offered are at low quality, then consumers can make a choice to attend on the private health service providers.

Our result shows that income represented by (GDP per capita) lower infant and under-five mortality in Tanzania. This means that, income influences health in a positive way and an important determinant of child survival (Byaro \& Musonda, 2016, O'Hare et al., 2013, Lopez, 2007). Early economic literature explores the link between income and health as a human capital in boosting economic growth (Bloom et al., 2004, Narayan et al., 2010) among others. In low-income countries, an increase in GDP per capita has high impact on reducing infant and under-five mortality (Issa \& Quattara, 2005). However, those countries which have reached a high level of development, a further increase in terms of income (GDP per capita) have a little impact on child mortality (Schell et al., 2007). Literature that reported a close relationship between income and infant and under-five mortality includes (Byaro \& Musonda, 2016, Emamgholipour \& Asemane, 2016, Meshkani et al., 2015, Asiedu et al., 2015, Holmes et al., 2015, Nishiyama, 2011, Filmer \& Pritchett, 1997, Filmer \& Pritchett, 1999, Bokhari et al., 2007, Musgrove, 1996). With regard to evidence on impact of income for reducing mortality, strong economic growth and development are crucial for countries to progress in tackling infant and under-five mortality. As noted out by Filmer \& Pritchett, (1999), "'Policies that encourage economic growth would do more for reducing child mortality than increasing public spending on health". Broadly, we can say that the impact of public health expenditure on child health outcomes is driven by other factors rather than public health expenditure.

In comparison with the results, we have used two statistical approaches to analyse data sets between 1995 and 2013. The results show that there is small difference between confidence values generated by the frequentist and that arising from the Bayesian method. We argue that the results are trustworthy given that both approaches give similar results. Researchers can adopt either approach depending on statistical preference among the user or modeling approach. However, in our study the frequentist approach seems to work well too and yield statistically significant results for variables of interest with sample size of 19 observa- 
tions. In contrast, frequentist approach is not reliable for very small sample sizes like 4 observations, while Bayesian can do.

\section{Conclusion}

From a theoretical point of view, financial resources (for example, government spending) play a crucial role in public health to achieve meaningful population health improvements. However, studying causal relationships between health expenditure and health outcomes is complex due to the fact that other sociodemographic and clinical factors contribute mortality.

Previous studies that found no association between public health expenditure, infant and under-five mortality include, (Ssozi \& Amlani, 2015,Deluna \& Peralta, 2014, Musgrove, 1996, Filmer \& Pritchett, 1999, Filmer \& Pritchett, 1997, Burnside \& Dollar, 1998, McGuire, 2006, Barlow \& Vissandjee, 1999), among others has been attributed to misallocations of overall public health expenditure due to corruption, poor policy, low institutional quality, poor incentive environment and weak administration capacity (Filmer et al., 2000, Burnside \& Dollar 1998). The broken to such misallocations comes between spending and services, not between services and survival (McGuire, 2006). If misallocation of overall public health expenditure was the case in Tanzania, we expect future research to shift this relationship of public health expenditure, per capita income and child health outcomes to specific interventions program (for example, public health expenditure on malaria and malaria specific under-five mortality).

Not only that, countries in middle and low income spent resources badly such that public health spending goes to expensive and nonessential services rather than essential health services which strongly impact on mortality (Cevik \& Tasar, 2013). Policy makers need to draw attention to the level or scope of input allocation to public health spending in developing countries (Cervic \& Tasar, 2013). The lack of public health expenditure to lower infant and under-five mortality in Tanzania suggests that more research should be done to find out other major determinants of infant and under-five mortality in the country. Previous studies (Byaro \& Musonda, 2016, Masanja et al., 2008, Susuman \& Hamisi, 2012) have been found that child immunization, ever breastfeeding, income, mother's education, attendant's births skills and antenatal care providers were associated with lower infant and under-five mortality in Tanzania. It is important to note that, perhaps allocating public health spending to specific interventions and program could impact stronger in lowering infant and under-five mortality rather than raise overall public health spending that might go to unnecessary health services (McGuire, 2006).

We conclude by arguing that, the effect size in this case was big even for sample size of 19 observations using frequentist approach. The sample sizes of 19 observations using the Bayesian MCMC yield the same results. The findings of this study have got some limitations. First is the lack of disaggregated data for public health expenditure. Musgrove, (1996) noted that "the data available on health spending do not permit disaggregation by type of intervention, thus it was impossible to judge the health impact of parts of that expenditure" (p. 44). Second, the result described throughout this study does not generalize the conclusion drawn to another setting due to different geographical location and different level of health spending and health outcomes.

\section{Authors Contribution}

Mwoya Byaro and Patrick Musonda were involved in the critical analysis from this study. Mwoya Byaro conducted the literature review, carried out the analysis and drafted the manuscript. All authors read and approved the manuscript. However, the conclusion and interpretation drawn to this article are entirely those of the authors. They do not necessary represent the views of Tanzania government.

\section{Acknowledgment}

Mwoya Byaro would like to thanks INTRA-ACP Mobility Scheme for providing financial support to him during entire Doctorate Programme at University of Zambia.

Last but not least, Patrick Musonda would like to acknowledge that some of his time is supported by the Research Council of Norway through its Centres of Excellence Scheme to the Centre of Intervention Science in Maternal and Child Health (CISMAC; project number 223269) and through the Global Health and Vaccination Programme (GLOBVAC; project number 248121). In addition, some of his time is also supported by the welcome trust; the Department for International Development; the Alliance for Accelerating Excellence in Science in Africa. Grant Number: [107754/Z/15/Z]. None of these organisations has contributed in any way in writing of this manuscript, any error arising in this publication is thoroughly the author's problem.

\section{References}

[1] Akinci, F., Hamid, S., Suvankulor, F., \& Akhmedjonov, A. (2014). Examining the Impact of Health Care Expenditures on Health Outcomes in the Middle East and North Africa Region. Journal of Health Care Finance ,41(1), 2-23.

[2] Akinkugbe, O., \& Mohanoe, M. (2009). Public Health Expenditure as a Determinant of Health Status in Lesotho. Social Work in Public Health, 24(1-2), 131-147. http://dx.doi.org/10.1080/19371910802569716

[3] Anand, S., \& Ravallion, M. (1993). Human Development in Poor Countries: On the Role of Private Incomes and Public Services. Journal of Economic Perspectives, 7(1), 133150.https://doi.org/10.1257/jep.7.1.133.

[4] Anyanwu, J., \& Erhijakpor, A. E. (2007). Health Expenditures and Health Outcomes in Africa. Delta State University Economic Research. Working Paper No.91 .http://www.afdb.org/fileadmin/uploads/afdb/Documents/Knowledg

[5] Asiedu, E., Gaekwad, N. B., Nanivazo, M., Nkusu, M., \& Yi, J. (2015). On the Impact of Income per Capital on Health Outcomes: Is Africa Different? Journal of Economic Literature, JEL F23, D72.

[6] Barenberg, A. J., Basu, D., \& Soylu, C. (2015). The Effect of Public Health Expenditure on Infant Mortality: Evidence from a Panel of Indiana States 1983-1984 to 2011-2012. Working Paper,University of Massachusetts.

[7] Barlow, R., \& Vissandjee, B. (1999). Determinants of National Life Expectancy.Canadian Journal of Development Studies, 20 (1), 929.

[8] Bidani, B., \& Ravallion, M. (1997). Decomposing Social Indicators using Distributional Data. Journal of Econometrics, 77, 125-139. https://doi.org/10.1016/S0304-4076(95)01809-3.

[9] Bloom, D. E., Canning, D., \& Sevilla, J. (2004). The Effects of Health on Economic Growth: A Production Function Approach. World Development, 32 (1), 1-13 https://doi.org/10.1016/j.worlddev.2003.07.002.

[10] Boachie, M. K. \& Ramu, K. (2016). Effect of Public Health Expenditure on Health Status in Ghana.International Journal of Health, 4 (1), 6-11.https://doi.org/10.14419/ijh.v4i1.5794.

[11] Bokhari, F. A., Gai, Y., \& Gottret, P. (2007). Government Health Expenditures and Health Outcome. Journal of Health Economics, 16 (3), 257-273.https://doi.org/10.1002/hec.1157.

[12] Burnside, C., \& Dollar, D. (1998). Aid,the Incentive Regime and Poverty Reduction. Policy Research Working Paper No. 1937, World Bank, Washington DC.

[13] Byaro, M., \& Musonda, P. (2016). Impact of Public Health Expenditure on Infant and Under -Five Mortality In Tanzania (1995-2013): An application of Bayesian Approach. Journal of Economics and Sustainable Developments, 7 (12), 178-187.

[14] Cevik, S., \& Tasar, M. O. (2013). Public Spending on Health Care and Health Outcomes:Cross Country Comparison. Journal of Business, Economics and Finances, 2 (4), 82-100.

[15] Deluna, R. J., \& Peralta, T. F. (2014). Public Health Expenditures, Income and Health Outcomes in the Philippines. MPRA , 1 -20.

[16] Demery, L., \& Walton, M. (1998). Are Poverty Reduction and Other 21st Century Social Goals Attainable? World Bank, Washington DC. 
[17] Dieleman, J. L. (2013). Three Essays on Government Health Expenditure.Unpublished PhD Dissertation, University of Washngton. https://doi.org/10.1177/1094428112457829.

[18] Elola, J., Daponte, A., \& Navarro, V. (1995). Health Indicators and the Organization of Health Care System in Western Europe. American Journal of Public Health, 85 (10), 13971401.https://doi.org/10.2105/AJPH.85.10.1397.

[19] Emamgholipour, S., \& Asemane, Z. (2016). Effects of Governance Indicators on Under-Five Mortality in OECD Nationals:Generalized Methods of Moments. Electronic Physician, 8 (1), 1747-1751.https://doi.org/10.19082/1747.

[20] Filmer, D., \& Pritchett, L. (1999). The Impact of Public Spending on Health: Does Money Matter? Social Science and Medicine, 49 (10), 1309-1323.doi.org/10.1016/S0277-9536 (99)00150-1

[21] Filmer, D., Hammer, J., \& Pritchett, L. (2000). Weaks Links in The Chain: A Diagnosis of Health Policy in Poor Countries. The World Bank Research Observer, 15(2), 199. 224.https://doi.org/10.1093/wbro/15.2.199.

[22] Filmer, Deon, \& Pritchett, L. (1997). Child Mortality and Public Spending on Health:How Much Does Money Matter? World Bank Policy Research Working Paper No. 1864.

[23] Gani, A. (2009). Health Care Financing and Health Outcomes in Pacific Island Countries. Health Policy and Planning, 24(1), 7281.https://doi.org/10.1093/heapol/czn044

[24] Gujarati, D. (2004). Basic Econometrics (4 Edition ed.). Washngton: Irwin and McGraw Hill,New York

[25] Gupta, S., Verhoeven, M., \& Tiongson, E. (2002). The Effectiveness of Government Spending on Education and Health Care in Developing and Transition Economies. European Journal of Political Economy, 18(4), 717 737.https://doi.org/10.1016/S0176-2680(02)00116-7.

[26] Hojman, E. D. (1996). Economic and Other Determinants of Infant and Child Mortality in Small Developing Countries:The Case of Central America and the Caribbean. Applied Economics, 28(3), 281-290.https://doi.org/10.1080/000368496328641.

[27] Holmes, H. A., Magoma, M., John, T., Levira, F., Msemo, G., Armstrong, C. E., et al. (2015). Tanzanias Countdown to 2015:An Analysis of Two Decades of Progress and Gaps for Reproductive,Maternal,Newborn, and Child Health,to Inform Priorities for Post 2015. The Lancent Global Health, 3(7), e396e409.https://doi.org/10.1016/S2214-109X(15)00059-5.

[28] Issa, H., \& Quattara, B. (2005). The Effects of Private and Public Health Expenditure on Infant Mortality Rates: Does the Level of Development Matters? University of Wales Swansea.

[29] Kim, K., \& Moody, P. M. (1992). More Resources Better Health? A Cross National Perspectives. Social Science and Medicine, 34(8), 837-842.https://doi.org/10.1016/0277-9536(92)90253-M.

[30] Kim, T. K., \& Lane, S. R. (2013). Government Health Expenditure and Public Health Outcomes:A Comparative Study Among 17 Countries and Implications for US Health Care Reform. American International Journal of Comtemporary Research, 3 (9), 8-13.

[31] Kruschke, J. K., Aguinis, H., \& Jo, H. (2012). The Time Has Come:Bayesian Methods for Data Analysis in the Organizational Sciences. Sage Journals, 15(4),722 -752.

[32] Lopez, C. (2007). Health and Economic Growth:Findings and Policy Implications. MIT Press.

[33] Masanja, H., Savigny, D. d., Smithson, P., John, T., Mbuya, C., Upunda, G., et al. (2008). Child Survival Gains in Tanzania:Analysis of Data From Demographic and Health Surveys. The Lancent, $371 \quad$ (9620), 1276 1283.https://doi.org/10.1016/S0140-6736(08)60562-0.

[34] McGuire, J. W. (2006). Basic Health Care Provision and Under Five Mortality: A cross National study on developing countries. World Development, $34 \quad$ (3), 425.https://doi.org/10.1016/j.worlddev.2005.08.004.

[35] Meshkani, Z., Karyani, A. K., Kazemi, Z., Shaahmadi, F., \& Arefi, Z. (2015). The Main Determinants of Under-Five Mortality Rate in OECD Countries: A Cross Sectional Study. International Journal of Pediatr, 3 (14), 421- 427. http:// ijp.mums.ac.ir.

[36] Musgrove, P. (1996). Public and Private roles in Health.In Technical Report 339. Washington DC: World Bank.

[37] Narayan, S., Narayan, P. K., \& Mishra, S. (2010). Investigating the Relationship between Health and Economic Growth. Empirical Evidence from a Panel of 5 Asian Countries. Journal of Asian Economics, $21 \quad 404$ 411 https://doi.org/10.1016/j.asieco.2010.03.006.

[38] Nishiyama, A. (2011). Economic Growth and Infant Mortality in Developing Countries. European Journal of Development Research, 23(4), 630-647.https://doi.org/10.1057/ejdr.2011.17.
[39] Nixon, J., \& Ulmann, P. (2006). The Relationship Between Health Care Expenditure and Health Outcomes. European Journal of Health Economics, 7(1), 7-18.https://doi.org/10.1007/s10198-0050336-8.

[40] Novignon, J., Olakojo, S., \& Justice, N. (2012). The Effects of Public and Private Health Care Expenditure on Health Status in Sub-Saharan Africa: A New Evidence from Panel Data Analysis. Health Economic Review, 2 (22).https://doi.org/10.1186/2191 1991-2-22.

[41] Ntzoufras, L. (2009). Bayesian Modelling Using WinBUGS. John Wiley and Sons, Inc.https://doi.org/10.1002/9780470434567.

[42] O' Hare. B., Makuta, I., Chiwaula, L., \& Zeev, N. B. (2013). Income and Child Mortality in Developing Countries: A Systematic Review and Meta Analysis. Journal of the Royal Society of Medicine, $106 \quad$ (10), 408-414 https://doi.org/10.1177/0141076813489680.

[43] Pritchett, L., \& Summers, L. H. (1996). Wealthier is Healthier. Journal of Human Resources, 31 (4), 841868.https://doi.org/10.2307/146149.

[44] Quintana, P. G., \& Nason, J. M. (2012). Bayesian Estimation of DSGE Models. Working Paper No 12-4,Federal Reserve Bank of Philadelphia, p. 12.

[45] Schell CO., Reilly M., Rosling H., Peterson S., \& Ekstrom AM. (2007). Socioeconomic Determinants of Infant Mortality: A Worldwide Study of 152 Low, Middle and High Income Countries.Scandnavia Journal of Public Health, 35(3), 28897.https://doi.org/10.1080/14034940600979171.

[46] Singh, S. R. (2014). Public Health Spending and Population Health. A Systematic Review. American Journal of Preventive Medicine, 47 (5), 634-640.https://doi.org/10.1016/j.amepre.2014.05.017.

[47] Ssozi, J., \& Amlani, S. (2015). The Effectiveness of Health Expenditure on the Proximate and Ultimate Goals of Healthcare in Sub Saharan Africa. World Development, 76, 165179.https://doi.org/10.1016/j.worlddev.2015.07.010.

[48] Susuman, S. A., \& Hamisi, F. H. (2012). Under-Five Mortality in Tanzania:Demographic Scenario. Iranian Journal of Public Health, 41 (12), 8-18.

[49] Wagstaff, A., \& Claeson, M. (2004). The Millenium Development Goals for Health:Rising to the Challenges: 169-174.

[50] WHO. (2000). The World Health Report:Health Systems,Improving Perfomance. World Health Organization.

[51] World Bank. (2015). World Development Indicators Database. Washington, DC: World Bank.Available online athttp://data.worldbank.org/data-catalog/world-developmentindicator.

[52] Yaqub, O., \& Yussuff. (2012). Public Health Expenditure and Health Outcome in Nigeria: The Impact of Governance. European Scientific Journal, 8 (13), 189-201. 